\title{
GENETICALLY MODIFIED AGRIFOOD TRADE: NECESSITY OR CONCERNS?
}

\author{
Nurliza \\ Staf Pengajar Fakultas Pertanian Universitas Tanjungpura \\ Jl. A. Yani Pontianak, 78124
}

\begin{abstract}
Genetically modified agri-foods are genetically modified using biotechnology. Genetically modified organisms (GMOs) advantages are the focus of much attention in world food markets. Genetically modified crop technology is claimed also to have great potential for the world's farmers and ultimately consumers, following initial success with genetically modified cotton varieties. Benefits for farmers could include greater productivity and less occupational health and environmental damage (e.g., fewer pesticides), while benefits to consumers include lower food prices and, potentially, enhanced attributes. Common genetically modified agri-foods include maize, soybeans, oilseed rape (canola), chicory, squash, potatoes, pineapples and strawberries. Genetically modified agri-foods are designed for greater resistance to pests and viruses, higher nutritional value and longer shelf life. However, their safety, potential risks and ethical concerns are still being debated. Laws to regulate labeling of genetically modified agri-foods vary. The public's perception of the risk of new technology is critical to its acceptance. Perception of risk, in turn, depends on the credibility of the source of the information and trust in the regulatory process.
\end{abstract}

Keyword: Genetically modified agri-food, trade, concerns, necessity

\section{Introduction}

Genetically modified agricultural products have widespread that change to all agricultural products system. Genetically modified agricultural product is now almost available in most supermarkets through international trade. As response, a number of bilateral and multilateral efforts made to find appropriate mechanisms in order to manage risk and maintain the openness of international markets.

In theory, foods genetically modified using biotechnologies are known as genetically modified foods. Genetic material is altered using non-traditional, laboratory-based methods; this is known as genetic engineering. Individual genes with specific desirable traits are transferred from one organism to another. Traditional breeding can achieve similar effects, but works over a much longer time span and is not as targeted as genetically modified. In addition, traditional breeding cannot transfer genes from unrelated species as is possible with genetically modified.

The use of genetic engineering techniques in agriculture and food production is seen as an exiting and valuable development by many people who welcome the improvements in production efficiency that they offer to farmers and the enhanced nutritional value that is envisioned to benefit consumers. The development of plants with such attributes aims at increasing farmer profitability, typically by reducing input requirements and hence costs. Over time, as the adoption of such lower-cost technologies spreads, this outward shift in the supply curve would lower the consumer price of food.

The strong consumer skepticism toward genetic engineering in some countries, particularly in Europe, will also define the trading environment in which developing countries must compete. The opponent objects strongly, raising environmental, food safety, and ethical concern. A majority of people in Western Europe, Japan and Australia, for example, want at least to have labels on products that contain genetically modified organisms (GMOs), while the most extreme opponents want to see genetically modified 
(GM) crops completely excluded from production and consumption in their country. United Kingdom has restricted China's processed food export because they may have contained traces of GM soybean from United State.

The emergence of genetically modified agri-foods has generated a variety of policy reactions in different countries. The most extreme of these could lead to trade disputes in the World Trade Organization (WTO). Regardless of whether developing countries are exporters or importers of agricultural crops, they will be affected by the biotech policies adopted in countries with which they trade, especially if international trade disputes concerning GMOs (Genetically Modified Organism) emerge.

\section{Necessity of Genetically Modified Agri-Foods}

Inexpensive, safe and nutritious foods are needed to feed the world's growing population. Genetic modification may provide: sturdy plants able to withstand weather extremes, drought-tolerant, and salt-tolerant crops; better-quality food crops; higher nutritional yields; inexpensive and nutritious food with more antioxidants; foods with a longer shelf life; and food with medicinal benefits.

\section{a. Higher yield}

It has been predicted that by 2025 there will be an annual shortfall of cereals for feeding the human population of 68.5 million tones. One possible solution is the use of genetically modified (GM) crops, which are already grown extensively (59 million ha of GM crops were planted in 2002) in the USA, South America, Africa and China.

It is also said that these foods grow faster than the foods that are grown in the traditional manner. Due to this, productivity increases, providing the population with more food. Though the seeds for such foods are quite expensive, their cost of production is said to be lesser than that of the traditional crops. The main reason for this is that these foods have natural resistance towards pests and insects and so, not many pesticides and insecticides have to be sprayed on them and making these foods less cost of production moreover if cultivated in vast quantities and large. The development of transgenic plants with enhanced agronomic traits aims at increasing farmer profitability, typically by increasing factor productivity.

Continued expansion in the use of transgenic crops will depend in part on the benefits obtained by farmers cultivating transgenic instead of conventional crops relative to the higher cost for transgenic seeds. So far the improvements have been not so much in increased yields per hectare of the crops but rather by reducing costs of production (OECD 1999).

\section{b. Withstand weather extremes; drought-tolerant and salt-tolerant crops}

It is claimed that the foods are a boon in places which experience frequent droughts, or where the soil is incompetent for agriculture, due to which it is difficult to grow normal crops. At times, genetically engineered food crops can be grown at places with unfavorable climatic conditions too. A normal crop can grow only in specific season or under some favorable climatic conditions.

Some foods and fiber crops have been modified to make them resistant to insects and viruses and more able to tolerate herbicides. The major crops that have been modified for these purposes, with approval from the relevant authorities, are; maize (corn), heat, rice, oilseed rape (canola), chicory, squash, potato, soybean, alfalfa, and cotton.

\section{c. Environmental benefits}

Genetically modified advocates argue that genetically modified agri-foods are better for the environment, it is resistant to attack by pests or disease, and farmers can reduce their 
use of pesticides and herbicides and the residual levels of these chemicals in the environment. However, development of resistance can undermine and even reverse this benefit. That is, genetic engineering in agriculture has mainly been used to modify crops so that they have improved agronomic traits such as tolerance of specific chemical herbicides and resistance to pests and diseases (James 2001).

\section{d. Nutritional enhancement}

Genetic modification can also be used to improve the final quality characteristics of a product to the benefit of the final consumer, perhaps via the food processing industry or livestock producers. Such traits may include enhanced nutritional content, improved durability and better processing characteristics. These foods are known to taste better. Another reason for people opting for genetically engineered foods is that they have an increased shelf life and so there is less fear of foods getting rotten quickly. One of the major advantages is that they help in controlling the occurrence of certain diseases. There are some foods that cause allergy to people when consumed. By modifying the DNA system of these foods, the properties causing these allergies are eliminated successfully.

Genetically engineered foods are said to be high in nutrients, and contain more minerals and vitamins than those found in traditionally grown foods. Genetic engineering can be used to increase amounts of particular nutrients (like vitamins) in food crops. Research into this technique, sometimes called nutritional enhancement. For example, vitamin $A$ enhanced rice, known as Golden Rice which is in an advanced stage of being developed for commercial use in China, it has potential of alleviating vitamin A deficiency problems in many developing countries. This could have profound implications in developing countries, especially among the poor where Vitamin A Deficiency (VAD) is a major problem (Sommer and West 1996). Needless to say these problems are greatest among the poorest households in developing countries (Zimmermann and Qaim 2002).

\section{Concerns of Genetically Modified Agri-Foods}

Despite those potential benefits, genetically modified agri-foods are attracting a high degree of attention among some consumer and community groups concerned about their potentially adverse impacts on food safety (e.g., 'Will they cause cancer?') and the environment (e.g., 'Will they lead to pesticide-resistant super weeds? Will we end up with just a handful of crop varieties supplied by even fewer multinational seed forms?). Actually, consumers' concerns about foods are based on worries not only about health but also about agriculture, ecology and food culture (Holm and Kildevang, 1996).

It has been claimed that negative attitudes towards GMF arose from low levels of public knowledge about GMF. Despite the increased use of GMF products, the process and application of this technology is not well understood and several recent surveys demonstrated the lack of understanding of GMF by the consumers (Kahveci and Özçelik, 2008). Different studies have shown that consumers differ in their attitudes towards genetic modifications in foods (Hossain et al., 2003). Previous studies indicated that Swedish consumers have a very negative attitude towards Genetically modified agri-foods (Magnusson and Koivisto Hursti, 2002). Sheldon (2001) asserts that the public concerns voiced in Europe are mainly a popular movement rather than an explicit attempt to introduce barriers to trade: consumers feel that they are bearing heavy risks while capturing few benefits. It's also said by students that the health effects of GMF as follows: causing gene mutation (96.3\%), allergic reactions (73.8\%) and environmental risks $(57.5 \%)$. The students considered that GMO increase the variety of food available for human consumption (36.8\%), nutritional value (36.8\%) and the efficiency of food production (28.1\%) (Ayaz et.al., 2011). 


\section{a. Scientist, community group and public concerns}

Scientists, community groups and members of the public concerns about genetic modification food include: (i) new allergens could be inadvertently created, allergens could be transferred from traditional foods into genetically modified foods but no allergic effects have been found with currently approved it; (ii) antibiotic resistance may develop, bioengineers sometimes insert a marker gene to help them identify whether a new gene has been successfully introduced to the host DNA, If genes coded for antibiotic resistance enter the food chain and are taken up by human gut micro-flora, the effectiveness of antibiotics could be reduced and human infectious disease risk increase even though the risk is very low but there is general agreement that use of these markers should be phased out; (iii) cross-breeding, genetically modified crops can cross-breed with surrounding vegetation, including weeds, transferring undesired characteristics; (iv) pesticide-resistant insects, the genetic modification of some crops to produce the natural toxin that could encourage the evolution of its, rendering the spray ineffective; (v) biodiversity, genetically modified crops on a large scale may affect the balance of wildlife and the environment; (vi) cross-contamination, plants bioengineered to produce pharmaceuticals may contaminate food crops; (vii) health effects, minimal research has been conducted into potential acute health risks of using it.

\section{b. Social and ethical concerns}

Social and ethical concerns about genetic modification include: (i) the possible monopolization of the world food market by large multinational companies that control the distribution of genetically modified seeds; (ii) concerns related to using genes from animals in plant foods. For example, eating traces of genetic material from pork is problematic for certain religious and cultural groups; (iii) animal welfare could be adversely affected. For example, cows given more potent genetically modified growth hormones could suffer from health problems related to growth or metabolism; (iv) new genetically modified organisms could be patented so that life itself could become commercial property.

\section{c. Government response}

Numerous governments are responding to those concerns, typically in conservative, command-and-control ways such as placing a moratorium on the production use (and hence importation) of products containing genetically modified organism (GMO) or, in cases where permission is granted to grow or sell certain GM crop varieties, mandating strict GMO labeling laws that necessitate expensive segregation and identity preservation systems to be used throughout the supply chain, such as EU. For that reason, exporters of food products understandably fear that they will find customers in food-importing countries discounting or refusing to buy their products if even subsets of the exporting country's farmers adopt genetically modified technology. So while these GM-adopting countries apparently have benefited in terms of lower production costs, they have lost market share to genetically modified free suppliers.

Some food-exporting countries such as Australia and New Zealand (ANZ) thus need to weigh the potential economic (and environmental) benefits from biotechnology development against any negative environmental risks associated with producing genetically modified crops, any additional costs of segregation and identity preservation through the supply chain to avoid adventitious (accidental) presence of genetically modified varieties in non-genetically modified shipments and allow consumers to choose between foods with and without GMOs, any discounting and/or loss of market access abroad for conventional counterparts to those specific crops which may contain GMOs, and any discounting and/or loss of market access abroad for other farm products because of what GM adoption does for ANZ's generic reputation as a 'clean, green' and 'safe food' producer (Anderson and Jackson, 2004). 
Producers in some countries may benefit from the establishment of segregated agricultural markets for GM and non-GM products, depending on three factors: (i) the strength of opposition toward GM products in important markets; (ii) the costs of segregating product throughout the supply chain; and (iii) the difference productivity between GM and non-GM production. These countries may choose to grow GM crops for (domestic or foreign) markets where consumers are indifferent as to GMO content, and to supply GMO-free products to markets where consumers are willing to pay a premium for this characteristic. Such a market development would be analogous to the niche markets that have developed over recent decades for organic foods.

\section{Conclusions}

Perception of risk, in turn, depends on the credibility of the source of the information and trust in the regulatory process. In many countries, the public appears to have lost its trust in the scientists and government dealing with modified agri-foods, making the acceptability of modified agri-foods uncertain. Of equal importance are the socio-economic factors that impinge on the viability of modified agri-foods produce. These include intellectual property protection, trade liberalization (through subsidy and tariff barriers in developed countries) and the intensity of bio safety regulations. The socio-economic interests of developed and developing countries may diverge and may even be contradictory in any one country. Acceptance of genetically modified agri-foods crops will thus depend on detailed issues surrounding particular crops and economies.

\section{REFERENSI}

James, Clive. 2001. Global Status of Commercialized Transgenic Crops. ISAAA Brief No. 18, Preview. International Service for the Acquisition of Agri-biotech Applications. Ithaca, NY.

OECD. 1999. Modern Biotechnology and Agricultural Markets: A Discussion of Selected Issues and the Impact on Supply and Markets. Directorate for Food, Agriculture and Fisheries. Committee for Agriculture. AGR/CA/APM/CFS/MD(2000)2, Paris: OECD.

Sheldon, Ian. 2001. Regulation of biotechnology: Will we ever "freely" trade GMOs? $77^{\text {th }}$ EAAE. Helsinki, Finland, 17-18 August.

Zimmermann, R. \& M. Qaim. 2002. Projecting the Benefits of golden rice in the Philippines. ZEF-Discussion Papers on Development Policy No. 51. Center for Development Research (ZEF), Bonn.

Ayaz, Aylin, Saniye Bilici, Muhemmet Fatih Uyar, Betül Ay, Sema Börekci, \& Emel Kök. 2011. Consumer acceptance, knowledge and attitudes towards organic and genetically modified agri-foods: a cross-sectional study among Turkish university students. HealthMED. Volume 5/Number 5/2011. Journal of Society for Development in New Net Environment in B\&H

Hossain, F, Onyango B, Schilling B, Hallman W,\& Adelaja A. 2003. Product attributes, consumer benefits and public approval of genetically modified agri-foods. International Journal of Consumer Studies. 27: 353-365.

Kahveci D \& Özçelik B. 2008. Attitudes of Turkish consumers towards genetically modified agri-foods. International Journal of Natural and Engineering Sciences. 2(2): 53-57.

Holm L \& Kildevang H. 1996. Consumers' views on food quality: A qualitative interview study. Appetite. 27(1): 1-14. 
Magnusson MK \& Koivisto Hursti UK. 2002. Consumer attitudes towards genetically modified agri-foods. Appetite. 39(1): 9-24.

Anderson, Kym \& Lee Ann Jackson. 2004. GM food crop technology and trade measures: Some economic implications for Australia and New Zealand. Agricultural Biotechnology Program. Discussion Paper No. 0408 November 2004. Center for International Economic Studies 